\title{
Efetividade do Órgão de Solução de Controvérsias da Organização Mundial do Comércio: uma análise sobre os seus doze primeiros anos de existência e das propostas para seu aperfeiçoamento
}

The Effectiveness of the Dispute Settlement Body of the World Trade Organization: an analysis of its first twelve years of existence and proposals for its improvement

MARCELO DIAS VARELLA*

Rev. Bras. Polit. Int. 52 (2): 5-21 [2009]

\section{Introdução}

O Órgão de Solução de Controvérsias (OSC) da Organização Mundial do Comércio (OMC) tem se revelado um instrumento efetivo para lidar com problemas comerciais globais e para aportar um grau mais elevado de segurança jurídica nas relações multilaterais. A efetividade demonstra-se tanto em relação aos prazos para a solução de litígios, relativamente curtos em função dos montantes em disputa, como em relação ao cumprimento das decisões pelos Estados. Este sistema trouxe inovações na lógica jurídica dos mecanismos internacionais de solução de controvérsias, conseguiu legitimidade na sociedade internacional e possibilitou a maior participação de todos os Estados, inclusive os Estados em desenvolvimento no sistema.

A Organização Mundial do Comércio foi criada em 1995 e inovou com um mecanismo de solução de controvérsias com dispositivos mais cogentes e rígidos do que aqueles do Acordo Geral de Tarifas e Comércio (GATT). Entre 1995 e julho de 2008, 378 contenciosos foram submetidos a sua apreciação, tornando-se um dos foros internacionais com maior número de contenciosos. Formulou um conjunto de decisóes que somam mais de trinta mil páginas de jurisprudência e asseguram previsibilidade de interpretações jurídicas sobre os diferentes acordos do sistema OMC e assim colabora para ampliar a segurança jurídica do sistema jurídico comercial internacional. Atualmente, pode-se dizer que as interpretaçôes

\footnotetext{
* Professor do mestrado em Direito das Relações Internacionais do Centro Universitário de Brasília - Uniceub (marcelodvarella@gmail.com).
} 
do OSC contribuem para a limitação de políticas públicas de estímulo comercial em todo o mundo e a evitar conflitos entre Estados, exercendo uma importante função preventiva.

A eficácia do sistema foi adquirida com o alto índice de cumprimento das decisões. Em poucos casos houve a implementação de retaliações comerciais autorizadas, porque a maioria dos contenciosos resultou no cumprimento espontâneo, mesmo por grandes potências econômicas, que preferem sofrer perdas pontuais em determinados temas, mas garantir a legitimidade do sistema como um todo.

No entanto, há críticas à efetividade e ao modo de funcionamento do OSC, sobretudo de Estados tradicionalmente menos ativos nos fóruns internacionais ou que não têm hábito de praticar retaliações comerciais autorizadas por mecanismos jurisdicionais, como instrumento de política comercial internacional. As críticas se fundamentam tanto na lógica dúbia do sistema: diplomático ou jurisdicional, como não cumprimento das decisões e até mesmo que o adensamento de juridicidade poderia ser ruim para a expansão do multilateralismo econômico, construído sobretudo conforme negociaçōes mais políticas do que jurídicas. $\mathrm{O}$ temor de contra-medidas não autorizadas ou maquiadas com a suspensão do Sistema Geral de Preferências estão entre os principais motivos pelos quais os resistentes defendem a não utilização de todas as medidas possíveis e autorizadas pelo Entendimento sobre Solução de Controvérsias.

Para discutir este tema, é útil traçar uma breve análise da experiência vivida pelo OSC nos seus primeiros anos de existência. Utilizaremos como fonte uma base de dados elaborada pelo Banco Mundial, que concentra grande número de informações sobre o OSC e seus relatórios ${ }^{1}$. Assim, tentaremos discutir primeiro a previsibilidade jurídica do sistema, o cumprimento das suas regras processuais, em relação aos prazos propostos e a participação dos diferentes grupos de Estados neste sistema. Será, então, possível tecer algumas conclusões sobre a efetividade das decisões e das mudanças no direito internacional com este sistema como um todo.

\section{Breve descrição do funcionamento do Órgão de Solução de Controvérsias nos seus primeiros doze anos}

O OSC segue um conjunto de regras processuais previsto no Entendimento sobre Solução de Controvérsias da OMC, um pequeno tratado com prazos específicos e procedimentos claros para cada etapa processual. Praticamente

1 A base de dados concentra informaçóes de 1995 à 31.12.2006. Algumas precisões metodológicas precisam ser detalhadas, para a melhor compreensão do artigo. Em alguns contenciosos, há vários membros envolvidos. Neste caso, os autores do estudo consideraram as partes bilateralmente, assim, em um contencioso com dois demandantes e três membros como terceiros interessados, face a um demandado, por exemplo, foram considerados cinco contenciosos (de cada um face ao demandado). O numero total de contenciosos considerados, 351 foi assim multiplicado por quase três, totalizando 965. Além disso, ao contrário das categorias utilizadas em outros estudos, Estados em desenvolvimento membros da OCDE foram considerados como Estados industrializados, notadamente México, China, Turquia e Coréia do Sul. 
todos os tratados da $\mathrm{OMC}$ se submetem a este sistema de solução de controvérsias $(\mathrm{JACKSON}, 2006)^{2}$, Ainda que não sejam cumpridos à risca em todos os contenciosos, os prazos mantêm-se relativamente curtos. O OSC é órgão jurisdicional, mesmo se a linguagem utilizada nos seus documentos iniciais sugira um mecanismo voluntário, não-jurisdicional ${ }^{3}$. Em um contencioso, podem existir até quatro etapas distintas: consultas; painel; apelação; e implementação. Todas estas fases são confidenciais e apenas as partes ou terceiros interessados, também Estados, podem ter acesso aos autos.

Na primeira fase, de consultas, os membros ${ }^{4}$ manifestam seu descontentamento com práticas comerciais consideradas irregulares em relação aos tratados que integram o sistema OMC. A pretensão do Estado ou Organização Internacional membros em recorrer ao OSC se valida tanto com a violação a um acordo comercial, quanto da frustração de expectativas legítimas de ganhos comerciais derivados dos tratados firmados, ainda que sem violação aos tratados (damnum sine injuria). As negociações devem começar em até 30 dias após a reclamação. Durante as consultas, os membros devem envidar esforços para encontrar uma solução amigável por um período de no mínimo 60 dias antes de ingressar no painel. A passagem da fase de consultas depende dos Estados e não do OSC, porque os Estados devem indicar o insucesso das negociações bilaterais e declarar sua vontade de ingressar com um painel.

Este prazo é utilizado também para a preparação do processo, de recursos materiais e pessoais. Terceiros interessados também podem mobilizar recursos para ingressarem ou como partes ou como intervenientes processuais. Nos primeiros doze anos de existência do OSC, a fase de consultas durou em média sete meses (MAVROIDS \& HORN, 2008). No entanto, praticamente metade dos contenciosos não passa desta etapa, sobretudo porque há acordo entre as partes ou porque se considera que os custos políticos e econômicos do processo serão mais elevados do que seus benefícios. Nesta etapa, o Presidente do OSC pode exercer o papel de bons ofícios, conciliador ou mediador ou indicar alguém para fazê-lo. As tentativas de bons ofícios, mediação ou conciliação antes do estabelecimento de um painel podem se desenrolar tanto em Genebra, quanto nos próprios Estados envolvidos.

Se não houver uma solução mutuamente ajustada, o membro pode solicitar a instauração de um painel, composto por três árbitros, escolhidos pelo Presidente do OSC, dentre uma lista de nomes indicados pelo conjunto de Estados, composta

2 Alguns tratados plurilaterais (não-obrigatórios) podem definir como o Entendimento de Solução de Controvérsias será aplicado.

3 Interessante notar que a tradução brasileira é uma das únicas que utilizam a expressão "controvérsias", de notação menos conflituosa, afastando-se dos originais em inglês e francês "disputes", "différends" e mesmo da expressão "litígio", utilizada em Portugal. Isso demonstra a intenção do Governo brasileiro de entender tal mecanismo como de caráter não-jurisdicional. Atualmente, uma parte importante dos teóricos já reconhece o caráter jurisdicional do OSC.

4 Utiliza-se a expressão membros e não Estados-membros, como de praxe, porque há sistemas regionais de integração membros, como as Comunidades Européias. 
por funcionários das representações diplomáticas ou da própria OMC, professores ou advogados. Interessante notar que os brasileiros estão entre aqueles com maior participação em contenciosos (19 nos primeiros 12 anos), apenas atrás dos indianos, suíços, neozelandeses e australianos. Alguns Estados muito ativos no OSC têm poucos nacionais figurando como árbitros. Apenas dois norte-americanos, por exemplo, figuraram como árbitros nos painéis deste período, mesmo se os Estados Unidos é o mais freqüente membro. No entanto, ainda que não tenha norteamericanos no painel, nota-se que a maioria dos árbitros tem formação nos Estados Unidos, o que de certa forma explica a inspiração na lógica jurídica norte-americana em diferentes decisões, num misto de common law com direito continental.

Após a constituição do painel, os árbitros têm até seis meses para proferir uma decisão, prazo que pode ser reduzido a três meses, em situações de urgência. Na prática dos primeiros doze anos do OSC, a maioria dos casos extrapolou o limite de seis meses, mas a média geral não passou de nove (MAVROIDS \& HORN, 2008). Neste curto espaço de tempo:

- Cada parte apresenta uma petição escrita, detalhando os pontos que pretende discutir;

- Há uma primeira audiência para apresentação do caso pelos demandantes;

- Há uma segunda audiência para contestação dos demandados e terceiros interessados;

- O painel pode solicitar a apresentação de documentos por peritos;

- O painel apresenta então um rascunho da sua decisão, para comentários das partes;

- Com base nos comentários das partes, prepara um relatório provisório, para novos comentários, e concede mais uma semana para os comentários finais;

- O painel pode, no âmbito do seu poder discricionário, reunir-se novamente com as partes, no prazo de até duas semanas e decidir eventuais pontos ainda imprecisos;

- Publica-se o relatório final, e este apenas pode ser negado por consenso dos membros da $\mathrm{OMC}^{5}$. Até hoje, todos os relatórios foram adotados.

Trata-se de um prazo reduzido, sobretudo porque esta fase se destina conhecer os fatos e analisar centenas de documentos. O relatório final é em seguida enviado a todos os membros para aprovação ou negação.

Pode-se recorrer da decisão do Grupo Especial ao Órgão de Apelação, em até 60 dias a contar da aprovação do OSC. O Órgão de Apelação, por sua vez, é composto por sete juízes, e três deles, escolhidos por sorteio, participam do julgamento de apelação. Nesta etapa, apenas questóes de direito podem ser levantadas, mas como nos tribunais brasileiros, há uma interpretação ampla e

5 Até agosto de 2008, havia 153 membros. 
questôes de fato associadas a questôes jurídicas são constantemente revistas em segunda instância.

O Órgão de Apelação tem entre 60 e 90 dias para proferir uma decisão. Neste período, deve dar prazo para resposta da petição de apelaçãa, e proferir uma decisão final sobre o contencioso. O relatório também entra em vigor com a aprovação do Órgão de Solução de Controvérsias, o que apenas não ocorre se houver consenso negativo dos membros. Nestes doze anos de existência, todas as decisões de apelação foram julgadas dentro dos 90 dias previstos e aprovados pelo OSC.

As decisões do Grupo Especial e, sobretudo do Órgão de Apelação são em geral densas em argumentos jurídicos, utilizam diferentes tratados multilaterais da OMC e, de forma subsidiária, fontes jurídicas de fora deste subsistema jurídico. Analisa um a um os argumentos jurídicos levantados e decide quais políticas ou normas do Estado violam os tratados multilaterais. Determina então que os Estados alterem os dispositivos incompatíveis conformando-os aos compromissos assumidos internacionalmente. Nota-se que há uma redução na proporção dos casos em que há apelação, o que parece ocorrer em função do aumento da previsibilidade do sistema, com a construção e confirmação de uma jurisprudência sobre os diferentes tratados.

Em geral, um pouco mais da metade das violações alegadas são confirmadas pelo OSC. Com a confirmação da violação, o membro derrotado deve se manifestar em até 30 dias após a adoção do relatório para dizer se irá ou não mudar sua norma ou política interna e pede um prazo para tanto, que pode variar de 15 a 18 meses. A definição do prazo também pode ser objeto de uma arbitragem, que dura por sua vez até 90 dias, o que não interfere no prazo total para implementação porque a decisão final sobre o prazo retroage à adoção do relatório. Em nove casos a cada dez, o Grupo Especial ou o Órgão de Apelação concluíram que havia ao menos uma violação dos compromissos firmados.

Decorrido estes prazos, em caso de continuidade de descumprimento, o membro vitorioso pode solicitar a imposição de sanções comerciais, que também são chamadas de medidas compensatórias ou suspensão de concessões comerciais. O próprio OSC utiliza estas expressões com maior ou menor rigor, conforme o contencioso. Não há prazo máximo para solicitar a autorização de sanções, mas na média, os Estados levam 225,94 dias para solicitar uma arbitragem por nãocumprimento, após o esgotamento do prazo anterior (MAVROIDS \& HORN, 2008). Este período de tempo é em geral utilizado para que os membros tentem novas negociações ou verifiquem a legitimidade das razões alegadas para o nãocumprimento. Estamos aqui às vésperas da mais dura medida conhecida pelo direito internacional em instrumentos pacíficos de solução de controvérsias. Antes de aplicá-la, os membros devem negociar um acordo por, no mínimo 20 dias e, se não houver acordo, constituir outro painel arbitral para determinar o montante dos prejuízos e as formas de compensação. Em geral, nesta etapa, o vencedor superestima seus prejuízos e, via-de-regra, o montante é reduzido pela arbitragem. 
No contencioso Comunidades Européias - Bananas, por exemplo, os Estados Unidos propuseram retaliações de US \$ 520 milhões, mas a arbitragem fixou este montante em US \$191,4 milhôes (WT/DS27).

Não há multas. Não é o Estado que paga o valor determinado. A compensação se opera com a retaliação comercial preferencialmente no mesmo produto ou setor comercial discutido no contencioso. Se não for possível, em outros setores. O mais comum é retaliar em bens, onde um simples incremento do imposto de importação causa prejuízos a outra parte e é mais fácil calcular os prejuízos impostos com as medidas. O prazo para a aplicação das retaliações pode ser de até 15 meses. Após este período, as medidas devem ser revistas e podem ser renovadas se o ilícito persistir. Na prática, os Estados não precisam aplicar as retaliaçôes por tanto tempo para induzir cumprimento, e a média desde a criação do OSC tem sido de 9,48 meses (MAVROIDS \& HORN, 2008).

O processo todo dura, portanto, até 18 meses na primeira e segunda instâncias, outros 18 meses para cumprimento, totalizando, com os atrasos mais comuns, até quatro anos, em caso de descumprimento. O prazo é bastante reduzido se considerarmos que se trata de contenciosos entre Estados ou Sistemas Regionais de Integração, com alta densidade jurídica, respeito ao princípio do contraditório e que envolvem quantias que ultrapassam facilmente um cem milhões de dólares e que por vezes chegam a quatro ou cinco bilhôes. Como vimos, apenas em alguns casos, houve desrespeito dos prazos pelo OSC, o que ocorreu, sobretudo, em casos complexos, nos quais houve a contratação de especialistas externos para realizar estudos econométricos, a exemplo do contencioso Estados Unidos - Emenda Byrd (WT/DS217/ARB/KOR e WT/DS217/ARB/JAP ), em que o prazo da arbitragem foi muito superior ao previsto.

\section{A legitimidade do sistema e seus benefícios}

Entre os principais benefícios do sistema de solução de controvérsias, encontramos com maior freqüência o fortalecimento de um sistema jurídico internacional mais guiado por regras jurídicas e menos pela força das potências mais fortes (mesmo um sistema orientado pela força ainda é predominante); procura a conformidade das partes, mais do que indenizações por prejuízos sofridos; resolve as disputas amigavelmente, evitando tensões e mesmo guerras; é rápido; cria precedentes jurisprudenciais e aumenta a segurança jurídica; preenche lacunas de interpretação e resolve ambigüidades nos tratados; promove o cumprimento das regras internacionais; ameniza assimetrias entre os Estados; concede entre os participantes o sentimento de um procedimento justo; contribui para que governos vençam resistências internas contra políticas que ferem o direito internacional (JACKSON, 2006).

Assim, o sistema de solução de controvérsias da Organização Mundial do Comércio ganhou legitimidade por diferentes razóes: a adoção constante dos 
relatórios pelo OSC, uma análise jurídica densa e relativamente uniforme ao longo das decisões, imparcial, um alto índice de efetividade das decisões, o que leva a uma maior participação dos países em desenvolvidos no sistema.

Adoção constante dos relatórios. No sistema de solução de controvérsias anterior, no âmbito do GATT, era necessário que todos os membros aceitassem o relatório para que o mesmo fosse adotado (consenso positivo). No novo sistema, é preciso a rejeição por todos, para que o mesmo não seja adotado (consenso negativo). Se no antigo GATT, raramente um contencioso chegava à fase de retaliação comercial, porque os prejudicados o impediam, agora é uma situação perfeitamente possível em caso de não-conformidade.

Densidade jurídica. Em todos os relatórios, nota-se um grande apego aos aspectos jurídicos da questão. Desde os primeiros relatórios, houve um esforço constante para construir interpretações uniformes sobre os diferentes conceitos jurídicos, à luz do direito internacional e de suas regras de interpretação. Mesmo se não há obrigatoriedade de respeito aos precedentes, na prática, nota-se que o OSC mantém suas posiçôes anteriores, num sistema misto, entre o direito continental e o common law, marcado pela interpretação rígida dos tratados da OMC com o abundante uso dos seus próprios precedentes.

De qualquer forma, é um subsistema bastante fechado, quase autopoiético. O recurso a outros tratados é realizado de forma subsidiária, com raras exceções a algumas regras gerais, como a Convenção de Viena sobre Direito dos Tratados. Interessante notar que, como houve um ganho de legitimidade e os membros preferem utilizar este tribunal internacional em detrimento da maioria dos outros, o direito da OMC de certa forma se impõe sobre os demais subsistemas jurídicos. Mesmo se no plano teórico, não há hierarquia no direito internacional, no plano prático, os tratados do sistema OMC são mais utilizados como fontes jurídicas do que outros e se sobrepõe aos demais quando há conflitos de normas. Esta prevalência das normas comerciais suscitou críticas de diferentes setores, como os ambientalistas, que nos anos 90 consideravam que a lógica econômica acabaria por neutralizar as conquistas do direito internacional ambiental dos últimos anos. Tais críticas foram mitigadas com a consolidação de uma jurisprudência relativamente favorável ao meio ambiente e à saúde pública .

Imparcialidade. Não se pode dizer que houve preferências políticas por Estados mais poderosos ou por temas mais sensíveis. A taxa de confirmação das irregularidades das alegaçôes é praticamente a mesma entre todos os grupos de Estados ${ }^{7}$. De certa forma, alguns temas politicamente sensíveis, como o meio ambiente, por exemplo, tiveram interpretações mais elásticas dos conceitos

6 Em especial Estados Unidos - Camarōes (WT/DS58/61); Comunidades Européias - Asbestos (DS 135); Comunidades Européias - Hormônios (WT/DS26/48), entre outros.

7 Uma exceção se refere ao índice de sucesso dos pedidos dos Estados Unidos e das Comunidades Européias contra Estados em desenvolvimento, que superou, em média, nos primeiros 12 anos do OSC, $90 \%$. Foram analisados os 144 relatórios proferidos,com 2369 pontos alegados, p. 21. 
utilizados, a partir de uma análise estruturada de riscos, mas que não é inovadora e apenas segue um modelo já consolidado nos tribunais internacionais das Comunidades Européias e mesmo dos Estados Unidos.

Até hoje, aproximadamente um terço dos membros já foi condenado a conformar sua legislação às normas da OMC (WILSON, 2007): sete membros apenas foram condenados uma vez: Brasil, Republica Dominicana, Egito, Guatemala, Indonésia, Tailândia e Turquia; dez membros foram condenados em mais de um contencioso: Austrália (2), Chile (2), Japão (4), Coréia (5), México (4), Índia (4), Argentina (6), Canadá (8) ${ }^{8}$.

Em geral, os Estados, mesmo aqueles com maior poder econômico, cumprem as decisões da OMC. As Comunidades Européias, com dezesseis contenciosos perdidos e, principalmente, os Estados Unidos, com 33 contenciosos perdidos, quase metade do total mundial, são os que mais sofreram derrotas no OSC. Na análise da própria instituição, Estados Unidos e Comunidades Européias conseguiram alterar e conformar suas normas ou políticas consideradas irregulares pelo OSC na grande maioria dos casos e tiveram dificuldades residuais em poucos contenciosos, sobretudo aqueles com necessidade de aprovação do Legislativo (WILSON, 2007). Isso é ainda mais importante, porque a quantidade de condenaçôes destes Estados é bastante grande, mais da metade de todos os contenciosos desde 1995. Mesmo que tais membros tenham condições econômicas para suportar retaliações, preferem se conformar e manter a legitimidade do sistema como um todo, ainda que setores específicos sejam prejudicados.

Nestes doze anos, o índice de cumprimento chega a $83 \%$ dos contenciosos, sendo que os $17 \%$ restantes tocam temas cujos contenciosos eram muito anteriores à criação da OMC, já estavam consolidados nos Estados e o novo sistema foi utilizado para tentar reverter situaçôes consolidadas. É o caso, por exemplo, dos contenciosos sobre o regime de importação de bananas, que envolveu dezenas de membros e já era polêmico nos anos 70 muito antes da criação da OMC; dos hormônios na carne bovina norte-americana, rejeitada pelas Comunidades Européias, sobretudo, em função das crises sanitárias como a vaca louca, que torna politicamente difícil a imposição da decisão da OMC nos Estados-membros da União Européia.

Note-se que dos mais de 350 contenciosos entre 2005 e março de 2007, apenas em 109 houve uma decisão, ou seja, não houve uma solução acordada entre as partes. Destes, houve cumprimento voluntário em uma grande maioria e apenas em 18 contenciosos (aproximadamente 5\%), houve pedido de retaliação. Apenas na metade deste total ( 9 casos ou 2,5\%) houve uma arbitragem para calcular a retaliação, porque nos demais houve acordo ou conformidade. Destes 9 casos, em 8 houve retaliação, uma vez que no contencioso EUA - Norma de 1916 (WT/DS 136), os EUA se conformaram antes da retaliação ser implementada (WILSON, 2007).

8 Considera-se 109 relatórios, excetuando-se aqueles proferidos no contexto do art. 21 (5) do ESC, quando já há um relatório anterior desfavorável e se considera que ainda persiste o descumprimento. 
O ganho de legitimidade do sistema trouxe diferentes benefícios. A ampliação da segurança jurídica das decisões possibilita previsibilidade e a formatação de políticas públicas de acordo não apenas com os tratados da OMC, mas com as interpretações consolidadas sobre tais tratados pelo OSC. Não há como negar que as decisões da $\mathrm{OMC}$, a segurança de que serão aplicadas e das eventuais retaliações geram uma certa auto-limitação dos diferentes órgãos legislativos e executivos em todo o mundo, numa busca clara de não criar regras que possam posteriormente ser questionadas pelo OSC.

Maior participação dos paises em desenvolvimento. No sistema anterior, do GATT, praticamente o abandonaram, e agora representam um terço das demandas. Mesmo assim, apenas oito países menos avançados participaram de contenciosos nos primeiros 12 anos, o que é muito baixo, sobretudo se considerarmos que na maior parte das vezes comparecem como terceiros interessados. O Brasil, por exemplo, que participou de apenas dois contenciosos no sistema anterior, é atualmente o sexto maior demandante, atrás apenas de Estados Unidos, Comunidades Européias, Canadá, Índia e México, e à frente de outros atores comerciais mais importantes internacionalmente, como Japão ou China. Ao todo, entre 1995 e 2006, o Brasil iniciou 31 contenciosos, participou como terceiro interessado em outros 34.

De qualquer modo, os dois maiores usuários do sistema são Estados Unidos e Comunidades Européias, mas que aparecem duas vezes mais no pólo passivo $(56,1 \%)$ do que no ativo (26\%). Em outras palavras, o sistema serve muito mais para os demais atores comerciais solicitarem a conformidade dos grandes do que o contrário. Outro dado importante: estes dois gigantes comerciais atuam mais contra Estados em desenvolvimento, do que contra Estados industrializados, ou um contra o outro (98 contenciosos $)^{9}$. Os grandes beneficiários do sistema são os Estados industrializados, à exceção de Estados Unidos e Comunidades Européias, que demandam duas vezes mais do que são demandados.

No entanto, o sistema de solução de controvérsias foi estruturado inicialmente não como um órgão jurisdicional, mas como mais um instrumento diplomático de solução de conflitos e isso é um problema para a consolidação da legitimidade do mesmo. Isso pode ser notado a partir de algumas características do sistema, como a confidencialidade dos procedimentos, que contribui para a desconfiança dos operadores jurídicos. Aos poucos, o caráter jurisdicional foi ganhando espaço face ao político. Já no primeiro contencioso, no caso Estados Unidos - gasolina, o Órgão de Apelações demonstrou que poderia reverter a decisão do Grupo Especial e, no contencioso Bananas III, a confirmação da possibilidade de atuação de advogados privados (WIELER, 2000). Por outro lado, a não-denominação ou melhor caracterização desde o início como um tribunal internacional possibilitou a aprovação do mesmo pelo Congresso norte-americano.

9 Estiveram presentes 90 contenciosos, a maioria deles como terceiros interessados (MAVROIDS \& HORN, 2008). 
Os próprios juízes já se manifestaram favoráveis à abertura do procedimento. A partir do contencioso Comunidades Européias - Asbestos, houve finalmente a regulamentação de um procedimento participação da sociedade civil (amicus curiae) (RUIZ-FABRI, 2005). De qualquer modo, prevalece a confidencialidade, o que contribui para a desconfiança no sistema.

\section{A originalidade da lógica jurídica da indução de conformidade do Órgão de Solução de Controvérsias}

As decisões do OSC/OMC declaram num primeiro momento que uma determinada prática do Estado (legal ou política) viola os compromissos internacionais assumidos. Na última fase, calcula-se o montante de prejuízos sofridos com a ilegalidade e se autoriza retaliaçôes comerciais, sem a possibilidade de contra-retaliação. Do ponto de vista do direito internacional, pouco importa se a norma violadora é uma norma administrativa ou legislativa. Importante é o resultado final da medida e sua conformidade com os compromissos internacionais. O direito internacional também não verifica se o valor normativo dos tratados no direito doméstico. Assim, não importa se a norma contrária aos tratados da $\mathrm{OMC}$ é posterior a sua adoção ou, se pelo direito interno, seja superior hierarquicamente ao tratado multilateral, casos em que, pelo direito brasileiro, teriam a força de suspender a eficácia dos tratados. Para o direito internacional, não importa sequer se a norma considerada irregular é a própria constituição do Estado. A declaração de irregularidade indica que o membro incorre em responsabilidade internacional e poderá sofrer as consequiências econômicas de uma eventual retaliação.

Talvez por isso, exista certa resistência dos juristas clássicos em aceitar a legalidade do direito da OMC. Na prática, o aumento da cogência das decisōes internacionais limita a capacidade soberana do Estado de mudar sua própria legislação, ainda mais marcante em Estados com grandes territórios e tradicionalmente voltados para si mesmos, como Brasil, China, Rússia, Índia ou Estados Unidos. A principal diferença do direito da OMC não é apenas jurídica, mas de como instrumentos de políticos e econômicos de indução ao cumprimento são previstos no próprio direito. Antigamente, no direito internacional clássico, um Estado podia simplesmente ignorar as sanções ou mesmo se desligar da organização, sem maiores repercussões, fazendo valer seu direito interno. Apenas em casos extremos, a sanção repercutia em retaliações mais importantes ou mesmo se tornava conhecida pelos cidadãos comuns. Hoje, há retaliações econômicas suficientes para mobilizar os setores internos a exercer instrumentos de pressão política sobre os governantes para que se conformem à decisão.

A diferença está no mecanismo jurídico encontrado para induzir a implementação das decisões. O cumprimento vem com insatisfação dos setores retaliados que pressionam o governo a agir, e não o Judiciário nacional, que 
internaliza uma decisão internacional. A lógica jurídica do direito internacional clássico não consegue explicar este fenômeno.

Poderíamos nos perguntar o porquê dos Estados mais ricos simplesmente não ignorarem a retaliação de um país mais pobre. Pior, o porquê de não os contraretaliarem declarada ou implicitamente. Não o fazem porque uma medida desta natureza deslegitimaria o sistema como um todo e, em pouco tempo, afastaria os demais membros do OSC. Qualquer Estado poderia simplesmente se retirar da $\mathrm{OMC}$, mas essa também não é uma opção, porque pelo avanço do processo de globalização econômica, seria muito difícil fazê-lo, mesmo os mais poderosos. Logo, a melhor alternativa continua sendo assumir as perdas pontuais, chegar à conformidade e obter ganhos globais.

As retaliações comerciais se operam, na maior parte das vezes por meio de aumento do imposto de importação sobre bens originários do Estado, normalmente $100 \%$ ad valorem. Deve-se privilegiar a retaliação no mesmo setor econômico afetado. Depois no mesmo tratado. Se não forem efetivos, em outros tratados, o que se denomina retaliação cruzada. A retaliação é realizada apenas pelas partes no processo que ganharam o contencioso. Estes produtos se tornam tão caros que há o impedimento das vendas, a perda de mercados. O simples anúncio de uma possível retaliação provoca a não confirmação de contratos e prejuízos para as partes. Perdem neste processo:

a) Os exportadores dos produtos sobretaxados, não necessariamente os mesmos que eram beneficiados pelas medidas irregulares;

b) Os consumidores, porque pagarão mais caro pelos produtos retaliados ou terão que substituí-los por outros produtos que antes não eram da sua preferência.

Logo, toda retaliação comercial tem um aspecto negativo para o mercado interno. Quando se aplica uma retaliação deve-se não apenas atingir setores importantes do Estado exportador, como setores que não prejudiquem em demasiado o Estado importador. Deste modo, a escolha correta dos setores é fundamental. A maior parte ocorre no setor de bens, $94 \%$ nestes primeiros doze anos (MAVROIDS \& HORN, 2008). Quando há forte desproporção entre os Estados envolvidos, dificilmente qualquer retaliação em bens é possível, porque mesmo se um pequeno Estado importador sobretaxar um produto de um poderoso exportador, dificilmente este irá mudar sua legislação em função dos danos causados, porque a perda de mercado seria muito pequena.

Em alguns casos, o setor que recebia o benefício da norma considerada irregular pelo OSC é um setor muito próximo ao governo e, portanto, dificilmente se induzirá a conformidade, exceto se o próprio setor for prejudicado ou então se o prejuízo incorrer sobre outro ainda mais forte politicamente. No contencioso Estados Unidos - Emenda Byrd, por exemplo, o governo Bush havia sido fortemente financiado pela indústria siderúrgica durante as eleições. Quando assumiu o poder, instituiu uma taxa sobre as importações de aço, que além de acarretar no aumento 
dos preços dos produtos importados, era destinada às indústrias siderúrgicas norte-americanas, ou seja, golpeava-se duas vezes a concorrência. Japão, primeiro Estado a obter sucesso neste contencioso junto ao OSC, concluiu que dificilmente conseguiria induzir a Casa Branca a acatar a decisão da OMC retaliando outros setores econômicos fortes. Decidiu então retaliar produtos com grande repercussão eleitoral dentro dos Estados Unidos, fabricados em Estados com maior número de grandes eleitores, ainda que de baixo valor agregado. Publicizou dentro dos Estados Unidos que o Governo Bush estava preferindo defender as siderúrgicas aos empregos dos Estados retaliados, ao que o governo norte-americano acabou cedendo.

A retaliação não é muito comum. Entre 1995 e março de 2007, houve autorização para retaliaçóes em apenas oito contenciosos, ou seja, em menos de 2,5\% do total. A tabela abaixo ilustra bem este cenário.

\begin{tabular}{|l|l|l|}
\hline Contencioso & $\begin{array}{l}\text { Montante autorizado/aplicado } \\
\text { de retaliações }\end{array}$ & Resultado final em março de 2007 \\
\hline $\begin{array}{l}\text { CE - Bananas III } \\
\text { (EUA e Equador) }\end{array}$ & US\$115 milhões, pelos EUA & $\begin{array}{l}\text { Acordo entre as partes, mas novos } \\
\text { recursos em 2008 }\end{array}$ \\
\hline $\begin{array}{l}\text { CE - Hormônios } \\
\text { (Canadá e EUA) }\end{array}$ & $\begin{array}{l}\text { US\$130 milhões pelos EUA } \\
\text { US\$20 milhões pelo Canadá }\end{array}$ & $\begin{array}{l}\text { Ainda em curso, mas em março de } \\
2008, \text { as retaliações foram julgadas } \\
\text { além do permitido }\end{array}$ \\
\hline EUA - FSC & $\begin{array}{l}\text { US\$ } 4 \text { bilhões pela UE, mas impostas } \\
\text { apenas em parte }\end{array}$ & $\begin{array}{l}\text { Houve acordo, após manifestação do } \\
\text { Congresso americano }\end{array}$ \\
\hline EUA - Emenda Byrd & $\begin{array}{l}8 \text { partes foram autorizadas a retaliar } \\
\text { os EUA. Japão, CE, Canadá e México } \\
\text { retaliaram. }\end{array}$ & $\begin{array}{l}\text { Em função de um acordo no NAFTA, } \\
\text { México e Canadá retiraram suas } \\
\text { retaliações. } \\
\text { Japão e CE continuam a retaliar. }\end{array}$ \\
\hline $\begin{array}{l}\text { Canadá/Brasil - } \\
\text { Aeronaves - Embraer } \\
\text { Bombardier }\end{array}$ & $\begin{array}{l}\text { Houve condenações mutuas em } \\
\text { diferentes contenciosos }\end{array}$ & Medidas nunca impostas \\
\hline
\end{tabular}

Fonte: Adaptado de WILSON, 2007.

Isso não significa que houve conformidade espontânea em todos os demais contenciosos, porque em alguns casos, os Estados vencedores preferiram não retaliar. No entanto, nota-se que os grandes partícipes do processo de globalização efetivamente usam suas possibilidades jurídicas para impor a conformidade dos demais Estados. Apenas em três contenciosos, ainda persistem retaliações (Emenda Byrd, Bananas III e Hormônios), mas são casos isolados que refletem problemas muito anteriores a OMC.

Discute-se agora a possível eficácia da retaliação cruzada, via outros setores, como propriedade intelectual ou serviços, quando há ofensa de tratados relativos a bens. É o caso do contencioso entre Brasil e Estados Unidos sobre o algodão. O Brasil considerou que seria ineficaz retaliar eventuais importações de algodão 
de origem norte-americana para o Brasil, porque o Brasil é um exportador de algodão e, quase não importa este produto. Também seria pouco efetivo retaliar em outros bens, porque o Brasil representa uma pequena parcela do total das exportaçóes americanas e medidas dificilmente incomodariam os exportadores a ponto de convencerem o Governo norte-americano a mudarem sua legislação agrícola de subsídios, sobretudo porque os agricultores são muito fortes politicamente. A solução foi eleger o setor de propriedade intelectual, onde o Brasil exerce um papel importante e com maior poder de pressão sobre o Governo norte-americano para convencê-lo a não sacrificar seus produtos em defesa dos subsídios agrícolas.

A retaliação em propriedade intelectual não necessariamente gera prejuízos para os consumidores brasileiros. Pode se operar sobre a remessa de royalties para o exterior, limitação temporal ou espacial de direitos de propriedade intelectual, mecanismos para forçar a transferência de tecnologia, licenças compulsórias para livros didáticos ou para que produtos farmacêuticos sejam produzidos por empresas brasileiras ou importadas de outros Estados onde sejam fabricados a preços mais razoáveis, o que poderia inclusive baratear custos para os nacionais. Poderia ainda tornar possível que o Brasil fizesse uma licença para uso público não-comercial e distribuísse os medicamentos gratuitamente ou até exportasse estes produtos agora fabricados por laboratórios públicos a Estados africanos, assolados por doenças graves, como a AIDS, por exemplo.

A retaliação cruzada em propriedade intelectual foi autorizada pelo OSC ao Equador, contra as Comunidades Européias e à Antígua e Barbuda, contra os Estados Unidos. No primeiro contencioso, houve acordo entre as partes. No segundo, os impactos negativos são tão pequenos, que não geraram conseqüências graves. De qualquer modo, os precedentes possibilitam agora que o Brasil possa fazer retaliaçóes com valores significativos. Os críticos ao uso deste instrumento pelo Brasil, no entanto, afirmam que o Brasil poderia ser considerado hostil comercialmente aos olhos americanos, por exercer seus direitos, talvez inclusive excluído do Sistema Geral de Preferências, pelo qual certos produtos brasileiros ingressam nos Estados Unidos com tarifas zero (um mercado de US\$ 3, 628 bilhões em 2005).

De qualquer modo, não acreditamos que os Estados Unidos irão contraretaliar, porque em diversos outros momentos quando foram retaliados, não o fizeram. De fato, podem excluir o Brasil do Sistema Geral de Preferências, o que talvez gere prejuízos da ordem de 400 a 500 milhões de dólares, porque muitos dos produtos beneficiados pelo SGP teriam preços impeditivos para a concorrência com outras potências, mas ainda que isso ocorresse, o país estaria recebendo benefícios da ordem de alguns bilhões de dólares e estaria mais livre para finalmente romper sua dependência histórica em relação ao SGP norte-americano, que já foi motivo para diferentes pressões para a adoção de políticas comerciais nacionais no passado. 


\section{Propostas de reforma do sistema}

Alguns autores defendem mecanismos para aprimorar o sistema de solução de controvérsias da OMC. As principais sugestôes sugerem sanções comerciais coletivas; a concentração das sançôes em benefícios para as empresas afetadas; a aplicação de multas pecuniárias aos Estados; e o efeito direto das decisões da OMC no direito nacional (CHARNOVITZ, 2001); a criação de procedimentos mais simplificados para possibilitar que causas de menor valor possam integrar o sistema; a publicidade das audiências e do processo de tomada de decisão (BROWN \&; HOEKMAN, 2007); maior estabilidade dos membros de grupo especial ou melhor atuação política na irradiação do direito da $\mathrm{OMC}$ dos membros do Órgão de Apelações (WIELER, 2000).

A aplicação de sanções comerciais coletivas, por um número importante de Estados contra aqueles que resistem ao cumprimento pode ser interessante, sobretudo quando há assimetria de poder econômico entre os Estados envolvidos. Se um Estado fraco não conseguir causar estímulos econômicos negativos suficientes ao Estado mais forte, um coletivo de Estados participaria das sanções. Esta solução encontraria seu limite no montante de prejuízos causados com a medida ilegal, que, na lógica atual, serve de teto para retaliação, ou seja, apenas quando o Estado fraco não conseguir impor sanções nos montantes previstos, teria a ajuda de outros. O sistema continuaria pouco efetivo quando o montante de prejuízos é pequeno para o Estado retaliado, situação bastante comum quando há assimetria de poder econômico entre os Estados envolvidos. Nesta situação, a efetividade da medida dependeria de desconsiderar a regra da proporcionalidade entre o montante da sanção e dos prejuízos, o que não é bem avaliado atualmente.

A concentração das sançôes em benefícios para as empresas afetadas significaria uma mudança de orientação lógica do sistema atual. Hoje, o sistema é fortemente estatocêntrico, e os sujeitos de direito internacional envolvidos, sobretudo a OMC, ignoram, via de regra, as empresas que sofrem os efeitos das medidas impostas quando decidem os setores que serão afetados. O objetivo central é atingir setores politicamente importantes, para induzir a conformidade à decisão e não buscar compensação por meio das medidas.

A aplicação de multas pecuniárias ao Estado, com recursos destinados a um fundo internacional, também significaria mudar a lógica do sistema, que hoje se concentra sobre a suspensão de concessões comerciais e não envolve o orçamento público. A medida dificilmente seria aplicada, por uma questão jurídica e outra política. Juridicamente, poucos Estados têm mecanismos domésticos para efetivar pagamentos de multas aplicadas por Organizaçóes internacionais. Politicamente, esta nova lógica suprime um dos principais benefícios do sistema atual, o fortalecimento do Estado por meio das medidas externas e da criação de disputas entre atores internos. 
O efeito direto das decisões significa a possibilidade de o Judiciário dos Estados dar efeito imediato à medida. É atraente para Estados que reconhecem a preponderância dos tratados sobre normas internas, porque consideraria ilegais normas posteriores contrárias aos compromissos firmados. No entanto, em outros Estados onde esta relação entre o direito nacional e o direito internacional não é tão clara, como no Brasil, poderia significar a ineficácia do sistema, porque a vigência do tratado poderia ser considerada suspensa (ou mesmo revogada) à luz da norma interna posterior. A efetividade das decisões dependeria do grau de monismo ou dualismo de cada Estado, gerando insegurança jurídica a todo o sistema. Além disso, o sistema dependeria da agilidade dos judiciários nacionais, que seriam alvo de processos internos por vezes muito mais morosos do que no âmbito multilateral. Em contenciosos como as Comunidades Européias - Pneus, onde a condenação se deve à própria ineficiência do Judiciário brasileiro em proferir em tempo razoável uma decisão definitiva, a medida seria ineficaz.

Discute-se também a proposta de criação de um procedimento mais simplificado, para atender a contenciosos envolvendo valores menos representativos, como aqueles que afetam, sobretudo, Estados em desenvolvimento. Talvez seja uma solução interessante, caso se adote procedimentos mais fortes para induzir o cumprimento, como a sanção coletiva, além do limite dos prejuízos sofridos ou outros mecanismos mais favoráveis aos países menos avançados.

Há um movimento importante, mesmo dos Estados Unidos em algumas ocasiões, para a publicidade do processo de tomada de decisão e das audiências. $\mathrm{O}$ sistema funciona de forma confidencial e, em alguns momentos, sequer os terceiros interessados podem participar das audiências. No contencioso Comunidades Européias - Hormônios, em função da importância social e sanitária do caso, a pedido das partes, o OSC possibilitou a publicidade de uma audiência, mas se trata de um caso raro. Os documentos apresentados e discutidos são muitas vezes sigilosos e a publicidade poderia comprometer as informações. Em função dos interesses políticos e econômicos envolvidos, há forte resistência dos Estados contra esta idéia.

Alguns autores defendem ainda a composição de uma lista mais estável de árbitros e o fim da exclusão automática do árbitro em função da sua nacionalidade e das partes em conflito. Na prática, já se pode dizer que existe certa estabilidade dos árbitros. As decisões do Grupo Especial nos anos recentes demonstram que o respeito pelas interpretações anteriores e a existência de certa organicidade, ainda que com alguma rotatividade de árbitros.

A organicidade vem, sobretudo, do importante papel desenvolvido pelo Secretariado, que na prática desenvolve as principais interpretações nos casos, o que também merece críticas da teoria jurídica. Acusa-se os juízes de não decidirem de fato, o que reduziria a importância principalmente do Órgão de Apelações, o que de fato parece ocorrer em diversos casos (WIELER, 2000). 
Por fim, seria possível e necessário que os membros do Órgão de Apelaçōes atuassem mais ativamente para a consolidação das posições da OMC no âmbito dos tribunais supranacionais e mesmo nacionais, de forma a evitar resistências e dar melhores condiçōes para irradiar as posiçōes da Organização. Atualmente, a legitimidade jurídica tem sido adquirida a partir da força das retaliações autorizadas e seria otimizada com a conscientização da importância do seu conjunto normativo também pelo Judiciário de cada membro (WIELER, 2000).

\section{Considerações finais}

Assim, o direito e a prática da Organização Mundial do Comércio contribui para uma nova dimensão no direito internacional contemporâneo. Novas metodologias de ação, normas mais cogentes e uma nova lógica para solução pacífica de controvérsias estão entre suas principais contribuições. Trata-se de um ramo do direito internacional com um mecanismo de solução de controvérsias ágil, com considerável efetividade e que tem conseguido aportar segurança jurídica a um ramo do direito profundamente marcado por disputas políticas de natureza econômica.

Esta experiência pode servir de inspiração para outros ramos do direito internacional, que caminham por outros caminhos, ou com uma cronologia própria. No entanto, enquanto prevalece esta evolução com velocidades diferentes de cada subsistemas do direito internacional, uma evolução policrônica, o direito internacional econômico acaba se impondo sobre outros subsistemas.

O novo cenário jurídico propõe também novas questôes a serem enfrentadas. Certo que tem um órgão de solução de controvérsias com relativa efetividade, mas ainda está longe de neutralizar as assimetrias de poder entre Estados. Talvez este seja o principal desafio para sua evolução, mas que somente irá ocorrer se os próprios Estados mais poderosos se dispuserem a sacrificar mais seu poder de ação em nome de maior segurança jurídica internacional.

Recebido em 27 de janeiro de 2009 Aprovado em 10 de julho de 2009

\section{Referências bibliográficas}

BROWN, C. P.; HOEKMAN, B (2007). Developing countries and enforcement of trade agreements. why disputes settlement is not enough. Discussion paper series, n. 6459. Centre for Economic Policy Research, www.cepr.org/pubs/dps/DP6459.asp, acesso em 14.08.2008

CHARNOVITZ, Steve (2001). Rethinking WTO Trade Sanctions. [http://ssrn.com/ abstract=256952 or DOI: 10.2139/ssrn.256952]. Disponibilidade em 10/07/2009.

JACKSON, J. (2006). Sovereignty, the WTO, and Changing Fundamentals of international law.Cambridge: CUP, p. 145 
MAVROIDIS, P.; HORN. H. (2008) The WTO Dispute Settlement System 19952006. Some descriptive statistics (World Bank 2008). http://siteresources.worldbank.org/ INTRES/Resources/469232-1107449512766/DescriptiveStatistics_031408.pdf, acesso em $29 / 09 / 2008$

RUIZ-FABRI, H. (2005) Le juge de l'OMC : ombres et lumières d'une figure judiciaire singulière in Revue Générale de Droit Internationale Public, v. 6, n.1, p. 39-84.

WIELER, J. H. H. (2000). The rule of lawyers and the ethos of diplomats: reflections on the internal and external legitimacy of WTO Dispute Settlement in Harvard Jean Monnet Working Paper.

WILSON, B (2007). Compliance by WTO members with adverse WTO Dispute Settlement rullings: the Record to date in Journal of International Economic Law 10(2), p. 397-403.

\section{Resumo}

O presente artigo tem com objetivo analisar a atuação do Órgão de Solução de Controvérsias da Organização Mundial do Comércio, entre os anos de 1995 e 2007. Trata-se de um dos principais fóruns de solução internacional de conflitos, sobretudo em função da quantidade de contenciosos, de Estados envolvidos e de valores. O texto procura destacar o cumprimento dos procedimentos previstos; a originalidade dos mecanismos de estimulo à obediência das decisões: o ganho de legitimidade do sistema com o tempo e as principais sugestões de reforma em discussão.

\section{Abstract}

This article analyses the performance of the Dispute Settlement Body of World Trade Organization, between 1995 and 2007. This organ is one of the most important fora for conflict resolution today, because the number of cases, states and amounts in dispute. I intend to study the fulfillment of proceedings; the originality of the mechanisms to induce compliance; the progressive legitimacy of the whole system and the main suggestions to reform it.

Palavras-chaves: Organização Mundial do Comércio; órgão de solução de controvérsias; efetividade.

Keywords: World Trade Organization; dispute settlement body; effectivenness. 